\title{
PODER PUNITIVO E PRODUÇÃO DO ESPAÇO: uma leitura de discursos institucionais sobre conflito e controle no centro de Salvador-BA
}

\author{
Lucas Matos $^{7}$
}

\author{
Palavras-Chave \\ poder punitivo/produção do espaço/ \\ criminologia/Salvador
}

\section{SUMÁRIO}

1. Introdução: Poder punitivo e produção do espaço. 2. Caminhos de pesquisa. 3. Configuração urbana e desigualdade em Salvador-BA: Pecados no "paraíso racial". 4. Observações de pesquisa: conflito, controle e produção do espaço no

Centro da cidade 5. Considerações finais: recolocando o problema. 6. Referências Bibliográficas.

\section{Resumo}

Este trabalho tem como problema central a atuação - material e simbólica - do poder punitivo como produtor de espacialidades urbanas, tendo como ancoragem empírica - Centro da cidade de Salvador no período de 2013 a 2016.0 recorte temporal se refere à gestão de ACM Neto na prefeitura da cidade, marcada pela adoção retórica do empreendedorismo urbano, tendo a segurança e ordem pública como temas políticos centrais. O percurso metodológico partiu de observação exploratória em torno da atuação das instituições de controle (Secretaria de Ordem Pública, Guarda Civil Municipal e Policia Militar) em situações cotidianas e especiais (como as festas populares) do Centro da cidade com a produção de notas descritivas e analíticas em caderno de campo. $\bigcirc$ eixo empírico central da pesquisa, contudo, são entrevistas com personagens importantes dessas instituições que exercem atividades de controle na região. A realização das entrevistas buscou escapar de maniqueísmos com a intenção de ler criticamente os discursos institucionais como um importante caminho de interpretação e levantamento de novas questões. A partir desses caminhos de pesquisa,o trabalho discute as interações entre controle e conflito social transgredindo os tradicionais binômios normativos lícito/ilícito penal e crime/punição e concentrando o olhar nas dinâmicas de produção da cidade potencializadas pela gestão diferenciada dos espaços, em um movimento de criminalização racializada que articula pessoas em situação de rua, trabalhadores de rua, prostitutas e autores de pequenos furtos,sob o signo comum de sujeitos da desordem e da criminalidade.

' Doutorando em Direito pela Universidade Federal do Rio de Janeiro. Mestre em Direito Penal pela Universidade do Estado do Rio de janeiro. Bacharel em Direito pela Universidade Federal da Bahia. Membro do Grupo Clandestino de Estudos em Controle, Cidade e Prisões. 


\title{
PUNITIVE POWER AND SPACE
} PRODUCTION: a reading of institutional discourses on conflict and control in the center of Salvador-BA

\author{
Lucas Matos ${ }^{2}$
}

\section{Key words}

electoral justice / local elections /

abuse of economic and political power / collegial decisions / result of the ballot box

\section{SUMMARY}

ntroduction: Punitive Power and space production. 2. Research paths. 3. Urban configuration and inequality in SalvadorBA: Sins in the "racial paradise".4. Research observations: conflict, control, and space production in the city Center 5. Final considerations: Replacing the problem. 6. References.

\begin{abstract}
This research has as central theoretical problem the action- material and discursive of the punitive power as an urban spatialities producer, taking in account as an empirical anchor the Center of the Salvador-BA city in the period from 2013 to2016.The temporal cut refers to the management of ACM Neto at mayor, marked by the rhetorical adoption of the urban entrepreneurship with security and public order as central political themes.
\end{abstract}

The methodological course was based on an exploratory observation about the performance of the control institutions (Public Order Department, Municipal Civil Guard and Military Police) in daily and special situations (such as the popular festivities) of the city Center with the production of descriptive notes and analytical data in field notes. The central empirical axis of the research, however, are interviews with important figures of these institutions that exercise control activities in the region. The interviews sought to escape manichaeism, with the intention of critically reading institutional discourses as an important way of interpreting and raising new questions. From these research paths, the paper discusses the interactions between control and social conflict overcoming the traditional normative binomials licit/criminal and crime/punishment and focusingon the city's production dynamics through the differentiated management of spaces in a movement of racialized criminalization that articulates homeless people, street workers, prostitutes and perpetrators of petty thefts under the common sign of subjects of disorder and criminality.

Doutorando em Direito pela Universidade Federal do Rio de Janeiro. Mestre em Direito Penal pela Universidade do Estado do Rio de janeiro. Bacharel em Direito pela Universidade Federal da Bahia Membro do Grupo Clandestino de Estudos em Controle, Cidade e Prisões. 


\section{INTRODUÇÃO: PODER PUNITIVO E PRODUÇÃO DO ESPAÇO URBANO.}

Esse trabalho tem como problema teórico central a ativação política - material e simbólica - do poder punitivo como produtor de espacialidades, ou seja, como agente positivo de configuração sócio-espacial. A pesquisa teve como ancoragem empírica - Centro da cidade de Salvador, capital da Bahia.A investigação foi desenvolvida no ano de 2016, a partir de uma estratégia metodológica que articulou observação exploratória em torno da atuação das instituições de controle (Secretaria de Ordem Pública, Guarda Civil Municipal e Policia Militar) em situações cotidianas e especiais (como as festas populares) do Centro da cidade com a produção de notas descritivas e analíticas em caderno de campo e entrevistas com personagens importantes dessas instituições que exercem atividades de controle na região.

Quando faço referência ao poder punitivo como agente político produtor do espaço no Centro de Salvador, refiro-me a um complexo prático-discursivo que mobiliza um discurso de combate à desordem e à criminalidade como elemento legitimador de intervenções nas dinâmicas sócio-espaciais da área; e materializa-se a partir da atuação concreta das agências de criminalização, muito especialmente a Polícia Militar (PM), Guarda Civil Municipal (GCM) e Secretaria Municipal de Ordem Pública (SEMOP).

Nesse sentido, destaca-se a tentativa de escapar do binarismo lícito/ilícito penal para uma leitura mais complexa dos mecanismos de controle de sujeitos e condutas no Centro da cidade, mobilizando a noção ilegalismos (FOUCAULT, 1987; TELLES, 2010). $\mathrm{Na}$ configuração da demanda por ordem no Centro de Salvador esse conceito é mo- bilizado em um sentido "não-categorial" (TELLES, 2010, p. 39), pois orienta questões particulares a partir da leitura do campo. A utilidade do conceito deriva da sua plasticidade que "permite colocar em perspectiva, em um mesmo plano de referência, transgressões múltiplas, sem dissolvê-las sob um nome comum ou em um amálgama confuso e indiferenciado" (TELLES, 2010, p. 41). A noção de "ilegalismos":

(...) permite rastrear essa transitividade entre o ilegal, o informal e o ilícito, que foi aqui o nosso ponto de partida, sem se deixar cativo, digamos assim, dos objetos e campos de objetivação postos, no que diz respeitos aos temas tratados pela economia, pela sociologia do trabalho, também pela sociologia urbana (o problema do formal - informal) ou pela criminologia (crime e delinqüência) (TELLES, 2010, p. 42).

Assim, pensar o controle punitivo no Centro de Salvador exige transgredir as barreiras do binômio crime-punição, e ampliar o olhar para a gestão diferenciada dos ilegalismos populares (FOUCAULT, 1987; BATISTA, 2003) amplamente consideradas, em uma dinâmica de criminalização que articula pessoas em situação de rua, usuários de substâncias psicoativas, trabalhadores de rua, prostitutas, autores de pequenos furtos e outros sob o signo de sujeitos da desordem e da criminalidade.

Nesse mesmo contexto, a chave de leitura conflito/controle leva a crítica criminológica à superação do campo restrito do sistema penal formal como objeto de análise. Note-se que a superação da auxiliariedade em relação ao direito penal - que definia os limites epistemológicos e o objeto da criminologia ortodoxa - é uma das marcas da 
criminologia crítica, aportada ao discurso jurídico como uma sociologia jurídico-penal (BARATTA, 2011). Nesse sentido, instituições de controle que reproduzem no espaço urbano o ethos punitivo das forças de ordem tradicionais (polícias) devem entrar nas agendas de pesquisa do campo.

Assim, esse trabalho interpreta o poder punitivo como configurador material e simbólico de espacialidades, a partir da demanda por ordem em Salvador no quadro de permanências das estratégias históricas de gestão urbana pelo controle social racializado, articuladas com rupturas produzidas pelos novos discursos e práticas, especialmente em relação à incorporação discursiva da razão neoliberal (DARDOT, LAVAL, 2016) à gestão urbana e da policização do espaço da cidade como principal mecanismo de contenção da conflitividade social.

Nesse sentido, em relação à criminologia produzida no Brasil é possível sugerir algumas questões. Se, por um lado, é indiscutível que se trata de uma criminologia eminentemente urbana, o campo costuma pensar o espaço das cidades a partir da velha noção de teatro das ações humanas, mero palco onde se desenvolvem os processos seletivos de criminalização. Essa abordagem negligencia o fato indiscutível de que as "geografias fraturadas das nossas cidades" (VARGAS, 2013, p. 17) constituem e reproduzem cotidianamente os privilégios raciais e classistas centrais para a interpretação do fenômeno da criminalização e do controle punitivo. A questão, de fundo metodológico, é que o espaço não é uma "simples tela de fundo, inerte e neutra" (SANTOS, 2005, p. 31), mas possui certa inércia dinâmica (SANTOS, 2005), sendo um elemento decisivo na configuração de determinada formação social.
Por outro lado, a "violência urbana" é tema recorrente nas pesquisas sobre urbanismo no Brasil, quase sempre pensada de forma reificada. Nesse contexto, a atualização das análises do urbano na nossa margem periférica parece exigir possibilidades analíticas que ultrapassem, no dizer de Vera Telles (2015), o relativo estranhamento mútuo entre os campos acadêmicos que tematizam a questão da punição e os estudos urbanos em geral.

Do ponto de vista criminológico, essa tentativa depende fundamentalmente de uma postura metodológica, já muito debatida no campo (ZAFFARONI; BATISTA, et al., 2011),que se concentra nos aspectos positivos do poder punitivo, ou seja, na perspectiva de não "centrar o estudo dos mecanismos punitivos unicamente em seus efeitos "repressivos", só em seu aspecto "sanção", mas recolocá-los na série completa dos efeitos positivos que eles podem induzir, mesmo se a primeira vista são marginais" (FOUCAULT, 1987, p.. 26). Isso significa interpretar o controle como função social complexa, levando em consideração a punição em suas relações com o "campo mais geral de outros processos de poder" (FOUCAULT, 1987, p. 26).

É essa dinâmica configuradora do poder punitivo que orienta a tentativa de articulação da criminologia com o urbano. Sobre os desafios interpretativos apresentados pelas cidades contemporâneas nas fricções entre poder punitivo e produção do espaço, Vera Telles (2015) sintetiza:

De um lado, os mecanismos de controle e seus modos operatórios se apresentam, já há algum tempo, cada vez mais, sob formas territorializadas, situadas, intricadas com a gestão dos espaços e gestão das populações - é o caso dos chama- 
dos controles situacionais, para ficar no exemplo talvez mais evidentes - e, que nos faz ver os mecanismos pelos quais - governo da segurança passa a se confundir com o governo dos espaços. (...) De outro lado, no caso dos estudos urbanos, os pesquisadores muitas vezes tratam dos dispositivos de controle e seus aparatos como algo que aparece como evidências do trabalho de campo, sem chegar a conferir um estatuto a esses mecanismos no desenho da cartografia política da cidade. E, mais precisamente, seu lugar na produção de territorialidades urbanas.(p. 20).

\section{CAMINHOS DE PESQUISA}

A observação não estruturada em torno da atuação dos mecanismos de controle - polícia militar,guarda municipal e Secretaria Municipal de Ordem Pública - em situações cotidianas e especiais (como as festas populares) do Centro da cidade constituiu elemento exploratório fundamental para a investigação. A observação, aqui, é pensada não como busca ocasional de informações, mas posta a serviço do problema de pesquisa claramente explicitado (LAVILLE; DIONNE, 1999). Assim, a observação produziu notas descritivas e analíticas em caderno de campo, a partir das imersões diárias no campo nos meses de janeiro, fevereiro, agosto e setembro de 2016.

O eixo empírico central da pesquisa, contudo, foram as entrevistas realizadas com personagens importantes nas dinâmicas de controle social no Centro de Salvador. Assim, realizei entrevistas com figuras chaves do processo estudado: o Chefe do Grupo de Apoio ao Turista (GAT), unidade territorial da GCM no Centro (Entrevista 01); o Comandan- te do $18^{\circ}$ Batalhão da Polícia Militar, unidade territorial do Centro (Entrevista 02);o Inspetor Geral da Guarda Civil Municipal, (Entrevista 03) e a Secretária de Ordem Pública do município de Salvador (Entrevista 04). Além disso, entrevistei o Presidente da Associação dos Dirigentes do Mercado Imobiliário de Salvador (ADEMI), (Entrevista 05), com o objetivo de entender a movimentação da iniciativa privada no Centro da cidade 3 .

As entrevistas foram realizadas sem a utilização de um questionário rígido, mas a partir de questões gerais em torno do problema da pesquisa. É evidente que as posições e perspectivas dos entrevistados consubstanciam, ao mesmo tempo, fragmentos das posições institucionais e opiniões pessoais. O ponto é que pelas funções chaves ocupadas, os personagens estão habilitados, em certa medida, a representar politicamente o discurso institucional.

A questão, portanto, não é fazer um julgamento das posições pessoais de cada entrevistado - que gentilmente me receberam em seu cotidiano de trabalho, cada um se tornando protagonista da pesquisa-, nem tampouco estabelecer maniqueísmos sobre quem é "bom" ou "mau", mas sim Ler criticamente os discursos como uma importante chave de interpretação dos processos analisados. Durante a realização das entrevistas - e também na análise posterior - não perdi de vista que o discurso é "o campo da manipulação consciente e o da determinação inconsciente" (FIORIN, 2007, p. 18). Assim, durante as entrevistas o interlocutor sempre:

Organiza sua estratégia discursiva em função de um jogo de imagens: a imagem que ele faz do interlocutor, a que 
ele pensa que o interlocutor tem dele, a que ele deseja transmitir ao interlocutor etc. É em razão desse complexo jogo de imagens que o falante usa certos procedimentos argumentativos e não outros (FIORIN, 2007, p. 18).

Por outro lado, o campo das determinações inconscientes expõe a maneira do interlocutor ver o mundo em uma dada formação social (FIORIN, 2007). Nesse sentido, "a semântica discursiva é o campo da determinação ideológica propriamente dita. Embora esta seja inconsciente, também pode ser consciente" (p. 19). Essas tensões estão sempre presentes no ritual da entrevista. E a análise das narrativas não exclui esses distanciamentos necessários. A questão, portanto, não é a verdade ou a falsidade dos discursos, mas os indícios que eles oferecem sobre os processos em curso.

\section{CONFIGURAÇÃO URBANA E DESIGUALDADE EM SALVADOR - BA: PECADOS NO "PARAÍSO RACIAL"}

As ruas e ladeiras de Salvador contam os (des)caminhos de uma velha cidade. O seu desenvolvimento territorial está relacionado com movimentos históricos de exclusão e segregação sociorracial no espaço urbano, e a atual conjuntura anuncia uma nova rodada nesse mesmo sentido. Por outro lado, Salvador historicamente também produz resistência, que tem como um dos motores as lutas em torno dos usos do espaço. Antonia Garcia (2009) lembra que a historiografia mais recente tem reconhecido que a formação territorial das cidades brasileiras não foi pacífica como contava a história oficial. No caso de Salvador, a "cidade rebelde é oposta àquela 'terra da felicidade', de negros bem integrados à ordem vigente, tão cultuada pelas elites baianas" (GARCIA, 2009, p. 133).
A resistência negra urbana na cidade colonial e, após a independência, na província imperial, deu-se de variadas maneiras: quilombos urbanos, terreiros de candomblé, rebeliões escavas; além da micropolítica, processos de resistência cotidiana à dominação e ao controle, na permanente tensão da negociação e do conflito entre escravos urbanos e senhores (SILVA, 1989). A questão territorial sempre foi importante elemento dessas disputas e esse legado segue nos embates travados por movimentos de luta por moradia, associações de bairros, movimentos negros, movimentos de mulheres, entre outros.

A produção do espaço urbano é, assim, dialética e conflitiva. É essa dimensão da configuração urbana que faz com que em Salvador a segregação seja confrontada por territórios de resistência e disputa cotidiana pelo espaço, como se vê na região do Centro Antigo ou nos bairros populares encravados - mesmo sem convite - nas áreas apropriadas pela elite branca, à exemplo da Orla Atlântica. Nessas regiões, contudo, ficam mais evidentes as distâncias simbólicas e a condição de exclusão urbanística, induvidosamente material, dos setores populares.

O marco histórico da exclusão urbana em uma cidade diaspórica colonial como Salvador é a arquitetura social da senzala. É na separação entre espaços dos senhores e moradia muito precarizada dos trabalhadores escravizados nas casas e sobrados do Centro Antigo que se constitui nossa exclusão originária (GARCIA, 2009). O historiador João Reis (1989) chega a sugerir que até os séculos XIX não havia na cidade uma dinâmica residencial pautada na segregação residencial, mas sim de exclusão e diferenciação material e simbólica nos espaços coabitados pelas eli- 
tes brancas, negros libertos e trabalhadores escravizados. O Centro da cidade, assim, era uma espécie de meltingpot residencial, o que aguçava as contradições e contribuía para a configuração da Salvador como uma "cidade insurrecional" (REIS, 1989)

Em um trabalho sobre as interfaces entre racismo e desigualdades urbanas no Brasil, Oliveira (2013) observa como a apropriação do mito da igualdade racial no urbano - noção fortalecida pela ausência histórica de segregação espacial legalizada - em cidades como Salvador oculta a constituição dos processos de exclusão e, também, os lugares de resistência política e cultural do povo negro.

Em Salvador essa questão ganha contornos particulares. A relevância cultural e política das tradições afro-brasileiras, e sua relativa aceitação/incorporação/apropriação pelas elites e pelo discurso institucional fez da cidade espécie de "berço do mito da democracia racial no Brasil" (BAIRROS, 1988) ${ }^{4}$. Nesse contexto, discutindo os pecados no "paraíso racial" soteropolitano, Luiza Bairros se interessava em questionar o fato de que:

Existe um grande vazio na produção do conhecimento sobre a situação sócio-econômica do negro baiano. Além dos estudos historiográficos, encontramos uma vasta lista de trabalhos que se ocupam de aspectos da cultura afro-baiana, especialmente o candomblé. Por um lado, isto evidencia a importância desta cultura enquanto elemento vivo e atuante na socie-

\footnotetext{
${ }^{4}$ A questão da potência ideológica dos mecanismos de apropriação é muito debatida. Sobre o assunto, Schwarcz (2012) localiza nos anos 1930 o período no qual o "mestiço transformou-se definitivamente em ícone nacional, em um símbolo de nossa identidade cruzada no sangue, sincrética na cultura, isto é, no samba, na capoeira, no candomblé, na comida e no futebol. Redenção verbal que não se concretiza no cotidiano" (p. 28). Mas a questão é complexa, pois o movimento de "apropriação" nem sempre é completamente de cima para baixo. A incorporação ou aceitação da cultura popular pelos "de cima" pode ser entendida também como parte das dinâmicas de conflito e negociação política dos oprimidos por ampliação de reconhecimento social (SILVA, 1989)
}

dade. Por outro sugere, pelo menos em termos de produção do conhecimento, que o negro só tem existência socialmente reconhecida em termos de cultura popular. A culinária, a religião, os folguedos são elementos sistematicamente lembrados para falar do negro baiano.

Esses assuntos ganham dimensão de mero folclore quando apropriados pelo discurso oficial, particularmente aquele ligado à propaganda e ao turismo. É importante observar que a circunscrição do negro a essa esfera tem representado uma forma nem sempre sutil de discriminação. Determinados elementos da cultura popular são erigidos em símbolos válidos para o conjunto da sociedade; no entanto, não se reconhecem seus criadores para fora desse contexto. (...) Portanto, a troca aparentemente livre de traços culturais entre vários grupos étnicos é insuficiente para deduzir a natureza democrática da estrutura social. O fato de a sociedade usar a cultura negra em seu benefício oculta, entre outras violências, um estado de dominação e preconceitos raciais (BAIRROS, 1988, p. 292-293).

Nessa pesquisa realizada em 1988, Luiza Bairros fez uma análise pioneira - a partir dos dados do censo de 1980 - sobre o padrão de desigualdade socioeconômica na cidade da Bahia, dando ênfase nas desigualdades ocupacionais, salariais e educacionais entre brancos e negros soteropolitanos. O quadro social estudado por Bairros (1989) apontava para a intensa desigualdade social na cidade, materializada pela diferenciação social entre negros e brancos, cujos índices socio-ocupacionais variavam, inclusive, internamente a cada estrato social. A partir dos dados analisados, a pesquisadora conclui que em Salvador a "manutenção das desi- 
gualdades raciais cumpre importante papel no processo de acumulação assentado em altas taxas de exploração da força de trabaIho" (p. 318).

Em que pese algumas conquistas importantes do movimento negro, especialmente em relação às políticas de democratização do acesso ao ensino superior, o quadro social soteropolitano segue marcado por intensa desigualdade racial. Além das elevadas taxas de desemprego, o exemplo do diferencial de rendimentos entre os grupos de cor ou raça é bastante ilustrativo. Nesse quesito Salvador supera a média nacional. No Brasil, brancos apresentam rendimentos médios mensais ( $R \$ 1538,00$ ) equivalentes a menos do dobro de pretos $(R \$ 834,00)$ e pardos $(R \$ 845,00)$. A cidade de Salvador, contudo, lidera o ranking do diferencial de rendimentos entre brancos e pretos (3.2 vezes) e fica em segundo lugar no que compara os rendimentos de brancos e pardos $(2.3 \text { vezes })^{5}$.

Esse panorama social mantém uma relação dialética com a apropriação do espaço urbano na cidade. Como já discutido, a moradia, o trabalho ou até mesmo a possibilidade concreta de circulação em cada lugar de Salvador, com seus desequilíbrios materiais e potenciais simbólicos, reflete e, ao mesmo tempo, reproduz e constitui os privilégios sociais e raciais.

\section{OBSERVAÇÕES DE PESQUISA: CONFLITO, CONTROLE E PRODUÇÃO DE ESPAÇO NO CENTRO DA CIDADE.}

Parecia um velho sobrado como os outros, apertado na ladeira do pelourinho, colonial, ostentando azulejos raros. Porém era imenso. Quatro andares, um só-

${ }^{5}$ Dados do último censo do IBGE (2010). Disponível em: http://biblio-
teca.ibge.gov.br/visualizacao/livros/liv54598.pdf. Acesso: O1de janeiro teca.ibg 2017 . tão, um cortiço nos fundos, a venda do Fernandes na frente, e atrás do cortiço uma padaria árabe clandestina, cento e dezesseis quartos, mais de seiscentas pessoas. Um mundo. (...) Operários, soldados, árabes de fala arrevesada, mascates, ladrões, prostitutas, costureiras, carregadores, gente de todas as cores, de todos os lugares, com todos os trajes, enchiam o sobrado. (...) Uma preta velha vendia acarajé e mungunzá na porta. (Jorge Amado, Suor, p. 10).

Essa é uma potente descrição literária de um cortiço no Centro de Salvador em meados do século XX. A arquitetura colonial imponente - com casarões, sobrados e igrejas - até hoje configura a paisagem de áreas como Pelourinho, Santo Antônio Além do Carmo e Comércio. Milton Santos (2008) pensava o centro velho de uma grande cidade como um teatro da luta entre tendências históricas, uma estrutura urbana especial, que constitui "uma verdadeira síntese, pois reflete, ao mesmo tempo, as formas atuais de vida da região e da cidade e o passado (p. 28).

As iniciativas de modernização de Salvador, repetindo padrões de expansão urbana de outras capitais brasileiras, não privilegiaram o Centro Antigo. A partir da conjugação de fatores como crescimento demográfico e interesses especulativos do mercado imobiliário constituíram-se novas centralidades comerciais e residenciais, especialmente a partir do eixo de crescimento da região do Iguatemi, além da criação do Centro Administrativo da Bahia, que deslocou uma série de atividades públicas para a Avenida Paralela, principal via rodoviária da expansão da cidade em direção ao litoral norte (CARVALHO, PEREIRA, 2009). 
Desse modo, hoje a região central da cidade - que possui baixa densidade populacional se comparada com outras áreas - é ocupada, de uma forma geral, por setores populares e médios (SANT'ANNA, 2003). O Centro de Salvador é um território negro. A região se transformou ao longo do século passado em localidade de moradia, ocupação, trabaIho e lazer eminentemente popular. Nesse contexto, o Centro pode ser definido a partir de sua potência política e cultural, que alimenta a resistência contra as dificuldades sociais e econômicas, o racismo institucional, movimentos de criminalização e, sem dúvida, as tentativas de branqueamento da área a partir do "retorno ao centro abandonado" das elites locais, subsidiadas pelo poder público.

Na década de 1990 o Governo do Estado da Bahia, sob o comando de Antônio Carlos Magalhães, iniciou um amplo movimento de "revitalização" do CHS. O reconhecimento da área como Patrimônio Cultural da Humanidade, em 1984, pela UNESCO, chamou atenção do Governo do Estado e da iniciativa privada para o potencial econômico de uma região da cidade que há muito sofria com o desinteresse do poder público. Assim, em 1991 o Governo do Estado lançou o Programa de Recuperação do Centro Histórico de Salvador (SANT'ANNA, 2003).

Em que pese a preservação do patrimônio arquitetônico, garantida pela aquisição de boa parte dos imóveis coloniais pelo Estado, os impactos sociais negativos do programa são hoje largamente denunciados, tanto na academia como por movimentos sociais. A intervenção removeu cerca de 1900 famílias, - 90\% das pessoas que moravam na área que se transferiram para bairros distantes ou, insistindo em morar no $\mathrm{CH}$, ocuparam imóveis abandonados ou (não) utilizados para fins de especulação imobiliária nas adjacências da área recuperada. A indenização média de R\$ 1.200 por família, por sua vez, foi abaixo do que o recomendado para ações urbanas desta natureza (SANT'ANNA, 2003).

Por outro lado, as dinâmicas sociais e econômicas prometidas não se concretizaram. As tentativas de substituição do turista nacional médio pelo turista internacional endinheirado não lograram êxito. Assim, não se concretizou a efetiva substituição da população local que circula na região, ainda hegemonicamente de classe média e popular, em que pese os impactos sociais inegáveis do processo de remoção. Diante desse quadro, o shopping pelourinho nunca se relacionou com as demandas do público majoritário da região, muito menos com a dinâmica terciária do resto do Centro Antigo, voltada para um consumo mais popular.

Em que pese o relativo insucesso - inclusive econômico - desse modelo excludente de intervenção pública e privada no CHS, não há sinais de uma ruptura que indique alterações no sentido das intervenções na região. Ao contrário, em um momento de radicalização da dinâmica de mercantilização do espaço urbano, as perspectivas de intervenção, agora em um sentido mais amplo, tendo o Centro Antigo de Salvador (CAS) como território de referência, apresentam-se como parte importante da retórica da cidade corporativa e empreendedora, criativa e com vocação turística6.

É a partir dessa conjuntura que a conflitividade social em torno da apropriação do território central da cidade tem se radicalizado. O conflito, aqui, pode ser observado

Essa perspectiva tem orientado as intervenções sociais e urbanísticas produzidas atualmente tanto pelo Governo do Estado da Bahia (Governador Rui Costa/PT) como pela Prefeitura Municipal de Salvador (Prefeito Antônio Carlos Magalhães Neto/DEM). 
sob duas óticas distintas. De um lado, a luta política organizada, através de movimentos de luta pelo direito à cidade, associações de moradores ou organizações do movimento negro. Por outro lado, é intensa a conflitividade do dia-dia do Centro de Salvador, expressão das contradições sociais no cotidiano dessa área da cidade. É especialmente nesse sentido que a retórica privatista e autoritária - muitas vezes produzida no interior dos poderes públicos - embaralha manutenção da ordem pública e combate à criminalidade, demandando politicamente a intervenção do poder punitivo. É nesse nó, dotado de especificidades no Centro de Salvador, que o poder punitivo incide como um agente na produção do espaço; um agente cada vez mais requisitado e ativado material e simbolicamente?.

Uma caminhada pela Avenida Sete de Setembro desvela um conjunto de interações, negociações e conflitos. Nessa tradicional avenida convivem moradores da área, um comércio diversificado - que inclui armarinhos, lojas de roupas íntimas, eletrodomésticos e bijuterias -, centenas de comerciantes de rua - baianas de acarajé, vendedores de água de coco, eletrônicos "falsificados" e tênis de origem incerta -, e muitos transeuntes andando em direção à Praça da Sé ou, em sentido contrário, indo para o Campo Grande.

Em meio a esse contexto, incidem as forças da ordem - policiais militares, guardas municipais e fiscais da Secretaria de ordem pública (SEMOP)-, atuando em defesa de uma determinada concepção de ordenamento ${ }^{7}$ Esse olhar sobre a conflitividade social cotidiana, cabe destacar, não se confunde com nenhuma perspectiva criminológica romântica e a-histórica que pensa o desvio, abstratamente considerado, como expressão da luta de classes. Pretendo considerar, em um sentido mais amplo, que as disputas em torno dos usos do espaço se dão de variadas maneiras, inclusive, muitas vezes sem um sentido explicitamente político. Essa forma de conflito, contudo, produz consequências polípolicas e sociais relevantes, em que pese não seja capaz de direcionar a a luta no âmbito da produção do espaço a partir de um projeto político coletivo coerente. e segurança. Em espaços complexos como esse, a relação entre os mais diversos atores não se resume a nenhum tipo de binarismo, mas corresponde a uma constelação complexa de disputas, negociações e conflitos em torno da apropriação da riqueza circulante e da gestão do espaço e suas regulações públicas e privadas.

Ao longo da pesquisa, percebi como o poder público define a ordem pública a partir do pretenso uso "correto" do espaço urbano, a depender da especificidade de cada local. A questão central, contudo, camuflada a partir de um discurso verticalizado de lei e ordem, diz respeito à definição política do que é o uso "certo" do espaço público.

Por outro lado, durante as "andanças" da pesquisa de campo pude observar que a ocupação das forças da ordem no Centro ${ }^{8}$ é decisivamente fragmentada com uma distribuição nada homogênea dos efetivos ao longo da região. Assim, algumas localidades específicas sempre contam com intensa presença policial, enquanto em outras, a ação policial só ocorre em sentido emergencial.

Nesse contexto, foi possível identificar um cordão de segurança que começa na Praça Castro Alves e se prolonga até a base da Ladeira do Pelourinho. O início dessa safety area tem como marco uma unidade "móvel" da PM permanentemente estacionada em frente à estátua do poeta. A Praça Castro Alves hoje abriga dois equipamentos culturais (o Espaço Itaú de Cinema e o Centro Cultural da Barroquinha) e fica nas proximidades dos dois maiores empreendimentos da iniciativa privada no CHS: o "Fera

${ }^{3}$ A Polícia Militar atua no Centro a partir do comando do $18^{\circ}$ Batalhão que conta hoje com 310 policiais, número considerado insuficiente para a área pelo comandante dessa unidade territorial (Entrevista 02). A Guarda Municipal, por sua vez, tem como base territorial o Grupamento de Apoio ao Turista (GAT) A base policial e o GAT se localizam no Pelourinho, coração do CHS e principal área turística da região. 
Palace Hotel" e o "Hotel Fasano", ainda não inaugurado.

No fim da Ladeira do Pelourinho encontramos outra "Base Móvel" da PM. No meio do caminho há um intenso policiamento na área da Praça da Sé e, muito especialmente, no Terreiro de Jesus, ponto de partida dos turistas na caminhada pelos monumentos históricos da região. Nessa região, é constante a presença de pelo menos 10 policiais militares, além de outra "Unidade Móvel", em frente à Igreja de São Francisco, mesma área onde fica a Delegacia de Apoio ao Turista.

A Guarda Municipal segue essa tendência. Algumas ruas internas do Pelourinho também são muito vigiadas, especialmente aquelas que contam com restaurantes requintados como à Rua das Laranjeiras que, além disso, fica nas proximidades de algumas vielas que ligam o Pelourinho à Cidade Baixa, identificadas pelos policiais e guardas da região como área do varejo de drogas.

A região do Comércio, área do Centro localizada na Cidade Baixa, não conta com o mesmo prestígio das forças policiais. $\bigcirc$ policiamento mais cotidiano se resume à área turística do Mercado Modelo, que sempre conta com rondas da Guarda Municipal. A atuação da Guarda Municipal, nesse contexto espacial, parece ser definida a partir da diferenciação de tratamento a depender da natureza do conflito e dos seus protagonistas. Assim, a depender do capital social do interlocutor, a resolução do conflito pode se dar sob o signo da cidadania ou da criminalização. De fato, observando o atendimento aos turistas por parte dos guardas alocados no GAT, percebe-se um preparo específico para a tarefa, desenvolvida com muita eficiência. Os guardas que atuam no Centro recebem treinamento específico, o que inclui estudo de línguas estrangeiras e capacitação no campo do turismo.

Por outro lado, a guarda municipal tem sido denunciada constantemente por movimentos sociais e militantes dos direitos humanos por sua prática seletiva e autoritária na gestão do espaço urbano no Centro, atuando como vetor de criminalização de sujeitos considerados "fora do lugar", virtuais responsáveis pela "desordem" e "criminalidade". Em uma das ações da guarda no ano de 2016 no Centro (Comércio), um morador de rua foi morto após ser atingido no abdômen por um disparo de arma de fogo.

Nesse contexto, a questão das interações entre o exercício de poder punitivo e a produção do espaço pode ser colocada em perspectiva crítica a partir da constatação de certo embaralhamento no discurso e na prática das forças de ordem entre desordem sócio-espacial e "criminalidade", ou, como sugere Vera Telles (2015), do esfumaçamento da distinção entre o "indesejável" e o "ilegal" na legitimação do controle sócio-espacial punitivo.

A questão não se reduz a mera retórica ou jogo de palavras. Em seus trabalhos etnográficos na cidade de São Paulo, Vera Telles (2010) nota como "a equação fácil" (p. 14) muitas vezes resolvida com dados estatísticos oficiais duvidosos e não demonstrados de forma adequada - que articula pobreza, desordem urbana e criminalidade, retroalimenta "a obsessão securitária que, também ela, compõe o cenário urbano atual, da mesma forma como alimenta os dispositivos gestionários" (p. 14)

No contexto específico do Centro de Salvador a atuação seletiva do poder punitivo está intimamente ligada ao discurso da "de- 
sordem". O referido embaralhamento faz com que a atuação do poder punitivo seja legitimada pela "necessidade" de ordenação, ao mesmo tempo em que o problema da "criminalidade de rua" exige intervenções urbanas de variados matizes, muito frequentemente com sentidos excludentes de um ponto de vista racial e de classe.

O Centro carrega há muitos anos o estigma de região abandonada, desordenada e insegura. A questão é que nos últimos anos as cidades voltaram a se interessar pelos seus "abandonados" centros velhos. A tradução do modelo da cidade coorporativa, empreendedora e competitiva para o contexto brasileiro ativou um movimento de "revitalização" dos centros. Otília Arantes (2000), em um texto seminal para a compreensão crítica desse fenômeno, destaca um cenário de intensos processos de gentrificação (revestidos pela ideologia da revitalização urbana), em grande parte relacionados com o reencontro entre cultura urbana e capital.

A capa do jornal A Tarde - veículo impresso de notícias mais tradicional da cidade - do dia 11 de setembro de 2016 é taxativa: "Novos negócios mudam a cara do Centro Antigo". O texto da notícia de capa traz elementos importantes sobre o processo em curso na região:

O Centro Antigo de Salvador pode até não recuperar o mesmo vigor dos anos 1960, mas deverá ganhar um novo fôlego ainda este ano no processo de revitalização. O início do funcionamento do Fera Palace Hotel, na rua Chile, em novembro, é um ponta pé inicial de um projeto da iniciativa privada que prevê novos restaurantes, bares, pizzarias, choperia, escritórios, moradias e hotéis na região. $O$ empreendimento se une a um conjunto de ações do poder público. A expectativa é que soteropolitanos e turistas voltem a frequentar a área (A Tarde, 2016).

O quadro descrito pelo tradicional jornal aponta para um modelo de "governança" territorial mais uma vez voltado restritivamente para a exploração econômica da vocação turística da área. O projeto "Bahia Design District", promovido pela iniciativa privada (Fera Empreendimentos Imobiliários), por exemplo, prevê uma grande reestruturação da Rua Chile, uma das principais vias do Centro Histórico. A empresa adquiriu 123 imóveis na área, alguns abandonados para especulação, e pretende transformar a paisagem tendo como ponta de lança do projeto um hotel de luxo, o Fera Palace Hotel. Muito próximo desse empreendimento, será inaugurado outro hotel luxuoso, da rede Fasano, em frente à Praça Castro Alves e voltado para a vista da Baía de Todos os Santos.

Essa dinâmica de "revitalização" dos centros está longe de ser homogênea e sofre importantes variações em cada cidade. É um movimento marcado por inflexões a depender das conjunturas políticas locais, além de muitas vezes apresentar muito mais força discursiva do que concretização dos planos político-econômicos. Em Salvador, ainda não é possível precisar os resultados do processo em curso, diante das possibilidades de resistência dos movimentos sociais, conjunturas políticas no âmbito governamental e, sem dúvida, a atuação sempre inconstante dos atores privados 9 . O ponto que interessa, contudo, são os efeitos concretos na

9 setor imobiliário local, por exemplo, ainda olha com ceticismo para a revitalização do Centro Antigo, promovida principalmente por atores privados de outros Estados ou internacionais. Em entrevista com Luciano Muricy, Presidente da ADEMI, ele reafirmou que a entrada do setor imobiliário local depende principalmente da indução do poder público e a criação de condições atrativas para investimentos no Centro (ENTREVISTA 05). Uma das condições, como não poderia deixar de ser, é a produção de uma imagem de área segura. 
paisagem sócio-espacial e, mais importante aqui, os mecanismos de controle punitivo que essa prática-discursiva tem mobilizado.

É precisamente nesse sentido que o discurso institucional destaca a "desordem" e "violência urbana" como obstáculos decisivos para a cidade alcançar o posto de cidade empreendedora e competitiva. O Centro assume protagonismo nessa questão:

O centro de Salvador... ele ficou muitos anos sem um olhar da ordem pública e eu sempre coloco que quando o Estado se afasta da missão, cada um faz a sua lei. O Estado independente da sua esfera, o papel é regular essa convivência social através das leis, das normas, da legislação, Quando o Estado deixa de cumprir a missão cada um faz a sua lei. O centro ficou abandonado durante muitos anos. Sem uma fiscalização efetiva (ENTREVISTA 04)

Assim, o discurso captado sobre a conjuntura da "ordem pública" no Centro da cidade destaca, de um lado, os avanços obtidos através da atuação conjunta da Secretaria Municipal de Ordem Pública, Guarda Municipal e Polícia Militar, contra um histórico de "abandono" no qual a "desordem" dava o tom em um território onde "cada um fazia a sua lei". Em sentido complementar, destaca-se sempre a necessidade de mais controle e ordenação como caminho necessário para o avanço social e econômico da região, em uma estratégia de criminalização das questões e dos conflitos sociais.

O movimento de "resgate" dos velhos centros urbanos está intimamente ligado à dimensão cultural (ARANTES, 2000) que protagoniza a prática-discursiva empreendedora em "cidades criativas" como Salvador. Nesse sentido, a apropriação da dimensão cultural aos ditames da cidade empreendedora for- jou o que Otília Arantes (2000) chama apropriadamente de "culturalismo de mercado" (p. 16).

O que interessa aqui, especificamente, é a curiosa relação que a dimensão cultural do modelo de cidade empreendedora mantém com os processos de controle sócio-espacial legitimados pela "necessidade de ordenação" de determinados espaços e contextos sociais específicos. Ao longo do trabalho de campo as tensões entre "ordem" e "cultura" apareceram em evidência tanto nas entrevistas, como nas observações diretas, especialmente no período das festas que ocorrem no verão soteropolitano.

O ponto de fricção aqui, portanto, é a convivência entre uma política urbana que supostamente privilegia a cultura e, em tese, valoriza a diversidade, e a ideologia da ordem, historicamente homogeneizadora. Nesse sentido, vale observar o que disse a então secretária de ordem pública:

Salvador tem uma cultura de festa. De som alto. Nossa cultura é essa. Nossa cultura, eu sempre digo, você faz um restaurante no alto não da certo. Abra uma garagem e bote um monte de mesinha na rua que vai dar certo, não é isso? Todo mundo gosta de comer um acarajé e tomar uma cervejinha, é bacana mesmo. Então nós não buscamos interferir na cultura. É ordenar. Não é ação repressora (Entrevista 04).

Essa "convivência" é claramente percebida pela entrevistada com certa tensão, indicada na preocupação em destacar a "necessidade" de ordenação, mas sem interferir na "cultura" através da repressão. O que importa desvelar, contudo, é que entre o "respeito à cultura" e à diversidade e a "ordenação repressiva" existe uma constelação de processos políticos, que implica a diferenciação 
entre qual é a "cultura" que deve ser protegida e quais atividades devem ser proibidas ou devem ter as dinâmicas sociais essencialmente alteradas pelo exercício da lei e da ordem.

Nesse ponto, posso destacar as diferentes abordagens discursivas relativas a duas expressões culturais de Salvador: a "segunda feira gorda da Ribeira" e a vida noturna no boêmio bairro do Rio Vermelho. Nenhum dos dois contextos está localizado no Centro, mas a comparação é útil para ilustrar o argumento aqui desenvolvido.

A Ribeira é um tradicional bairro da Cidade Baixa, parte da Península de Itapagipe, na orla sul de Salvador. A "segunda-feira gorda" é uma festa popular do bairro que acontece na segunda-feira posterior ao dia de Senhor do Bonfim. A festa - que já foi uma espécie de abertura do carnaval soteropolitano hoje resiste com dificuldades a um quadro de esvaziamento. $\bigcirc$ poder público reagiu às denúncias sobre situações de violência na "Segunda Gorda" e aos alarmes da mídia sobre a desordem do local com um "choque de ordem", que contribuiu para esvaziar a tradição. A secretaria de ordem pública comentou longamente a situação na Ribeira:

Nós fazemos a operação PAl - Plano de Ação Integrada - em pontos específicos ou de acordo com a demanda. Hoje nós temos a operação PAl na Ribeira, por exemplo. Logo que eu assumi tinha - foi inclusive onde surgiu o modelo da operação $\mathrm{PAl}$, que hoje tá se consolidando - um problema na Ribeira chamada "Segunda Feira Gorda da Ribeira". Só que a "Segunda Feira Gorda" era um horror.Butijão de gás explodia e queimava as pessoas, tinha morte, tiro, estupro, paredão, em um dia de segunda-feira, sem hora para terminar. Quer dizer, o outro dia é terça. Ribeira um bairro misto, comércio e residência. Os moradores reclamavam que no outro dia tinham que acordar para ir para o trabalho. Como você dorme se o som do carro ta até duas, três horas da manhã. Como você consegue dormir com multidão na frente de sua casa, bebendo, comendo, gritando. Prostituição infantil na praia. Poluição sonora, tudo desregulado. A ordem pública, que seria os agentes de fiscalização, que são servidores concursados com o poder administrativo, eles podem apreender e a Guarda municipal sozinha não iria dar conta. Aí nós fizemos uma reunião e convidamos SUCOM, TRANSALVADOR, POLÍCIA MILITAR, SEMOP e Guarda Municipal e daí nasce a ideia, começou a surgir a operação integrada que depois nominamos de operação PAI. A Ribeira que nós fizemos e hoje é praticamente uma área ordenada. Você não houve mais falar da Segunda Feira Gorda. Ela não acabou. Mudou o formato. Hoje é a segunda feira gorda tradicional, que tem o cozido, o pirão, mas não tem mais a bagunça. É..., para não parecer que nós somos..., nós não queremos interferir na cultura local nós queremos apenas a ordem pública resgatada como fator de garantia de segurança pública (ENTREVISTA 04).

O Rio Vermelho, por sua vez, é outro tradicional bairro da cidade, que tem sua dinâmica social muito ligada à vida cultural noturna. O bairro passou por um amplo processo de "revitalização" no ano de 2016, constituindo uma das principais bandeiras da atual prefeitura. A reestruturação do bairro, todavia, foi bastante criticada por movimentos de moradores como o Rio Vermelho em Ação, que ao longo da "requalificação" questio- 
nou algumas escolhas urbanísticas e a falta de participação popular na elaboração do projeto.

Em que pese a noite do Rio Vermelho já fosse hegemonizada por setores médios e médios altos, a reestruturação tem um sentido excludente, simbolizado no aumento médio dos preços nos estabelecimentos e na atuação intensa da guarda municipal na repressão de trabalhadores de rua e demais figuras consideradas "fora do lugar". O formato da noite cultural do bairro, contudo, segue em disputa e provoca discussões na cidade:

Tanto é que agora no programa da metrópole com Zé Eduardo ${ }^{10}$, eu tive muito embate com ele quando ele me entrevistava, por que ele diz que o Rio vermelho é uma baderna. E eu fui contra ele. Não cabia a ele adjetivar. Eu não acho que é uma baderna. Ali é um movimento sócio-cultural. Um antropólogo pode explicar. Onde jovens devárias tribos se encontram. Isso não é uma baderna. Qual o papel da ordem pública? Tanto que ele ficou muito tempo em meu pé por que eu dizia que não ia reprimir o movimento dos jovens. Por que ali tem comunidade LGBT, por que tem a San Sebastian. Tem a comunidade alternativa, por que o bairro é um reduto cultural. Tem a turma de esporte, por eu ali tem uma quadra. E ai você vai ali e você vê gente, tribos. Ele dizia que "suas tribos" é tribo da bagunça. Eu dizia que não. Se eu tivesse vinte e poucos anos estaria ali. Ali seria o ambiente que eu acho que atrai um jovem de vinte anos. Eu já passei do tempo. Qual o papel nosso? Ordem pública para garantir a segurança. Coibimos garrafas de

\footnotetext{
O apresentador Zé Eduardo é um conhecido âncora local de programas televisivos policialescos. Conhecido como "Bocão", o apresentador vocaliza um discurso de lei e ordem radicalmente conservador e alimentado por estereótipos.
}

vidros, excesso de ambulante. Ali não é festa de largo. Ai o pessoal diz, mas ali não vai dar o ambulante? Não. Não tenho que dar licença. O ambulante tem os espaços legítimos para atuar. O Rio Vermelho ali é o dia-dia, do bairro. Não é o 2 de fevereiro. Então não vou licenciar ambulante de isopor, se não vai virar uma festa de largo. Vamos licenciar baiana de acarajé, beiju, cachorro quente, pipoqueiro. Mas ambulante de isopor não. (ENTREVISTA 04)

O debate da secretária com o radialista local é interessante em vários aspectos. Ela defende a diversidade da noite do Rio Vermelho, que, segundo ela, consubstancia um "movimento sócio-cultural", digno de estudo antropológico. O que importa notar, todavia, é que nessa festejada "diversidade" projetada nas várias tribos da juventude de classe média, é possível captar uma tendência de homogeneidade racial e de classe, em uma área que, mesmo antes das intervenções de revitalização, já era ocupada hegemonicamente pelos setores médios da cidade ${ }^{11}$. Importa notar, assim, que a tensão entre "ordem" e "manifestação sociocultural", nesse contexto, direciona-se para a manutenção e radicalização dessa homogeneidade.

A "Segunda Feira Gorda", por outro lado, festa popular e negra, é considerada desde o início da sua descrição um "problema" e um "horror". O ponto é que a incidência da ordem pública, aqui, foi mais radical, chegando ao limite de que "ninguém mais houve falar" da festa. O reconhecimento do valor cultural da "segunda gorda", por outro lado, não foi um ponto de partida para a narrati-

"É fundamental notar a complexidade desses processos urbanos e a necessidade de matizar interpretações. As intervenções elitistas no Rio Vermelho e os processos de controle não significaram homogeneização total da região, pois moradores de enclaves populares próximos resistem e frequentam o bairro, utilizando, inclusive, aparelhos urbanos reformados no processo de requalificação, à exemplo de um campo de futebol à beira-mar. 
va, mas mobilizada como uma ressalva politicamente necessária para não deslegitimar a "ordenação", "que não quer interferir na cultura local, apenas ser um fator de segurança pública".

O que interessa é perceber que a relação entre ideologia da ordem e preservação da cultura local varia a depender do contexto sócio-espacial. Nesse mesmo sentido, uma prática social como o trabalho de rua, a depender do contexto pode ser deslocado de um problema de "ordem pública" para a categoria de característica cultural da cidade, a ser reconhecida e protegida.

Poucos dias antes do início dos Jogos Olímpicos de 2016, a prefeitura de Salvador anunciou em sua página oficial que a cidade seria "a única cidade olímpica a permitir o comércio informal perto da Arena"12. $\mathrm{Na}$ ocasião foram credenciados cerca de 200 trabalhadores que comercializaram produtos da patrocinadora do evento e 07 baianas de acarajé.

A homogeneização dos espaços, movimento que acompanha a realização desses megaeventos do capitalismo, especialmente pela obsessão por segurança, articula-se com as experiências típicas da localidade, rigidamente controladas. O turista, assim, pode comprar uma bebida e comer um acarajé como se estivessem andando por Salvador, sem abrir mão dos esquemas de conforto e segurança que orientam a realização dos Jogos Olímpicos. É a vivência da experiência típica em um ambiente homogeneizado.

Por outro lado, a figura do ambulante apareceu na pesquisa como um elemento cha-

Disponível em: http://www.agenciadenoticias.salvador.ba.gov.br/ index.php/pt-br/releases-2/esportes/4260-salvador-e-unica-cidade-olimpica-a-permitir-comercio-informal-perto-da-arena. Acesso em: 01 de fevereiro de 2017. ve da dinâmica e do discurso de lei e ordem no Centro de Salvador. Na cidade da Bahia o trabalho informal extrapola as questões sociais do mundo do trabalho. Em Salvador, especialmente no Centro da cidade, o "ambulante" é um importante agente produtor do espaço e, a partir dos atuais parâmetros de governança, um problema para a ordem pública e segurança.

A prefeitura comandou um intenso processo de ordenação do mercado informal no Centro, em uma dinâmica de regulamentação de alguns ambulantes, e, por outro lado, proibição das atividades e criminalização da maioria:

Nós temos dois critérios. Isso é importante. Quando peguei a secretaria a Avenida Sete tinha na época 5.000 ambulantes. Eles falam nesse número. Eu não acredito que tinha isso tudo. Mas se hoje tem 1.500 ordenados eu diria que poderia ter o dobro. Pois a Avenida Sete é o sonho de consumo de todo trabalhador informal. Tem movimento todos os dias. Aí nós começamos a fazer reuniões por rua e estabelecemos dois critérios. O primeiro é a existência prévia da licença. A segunda antiguidade. (Entrevista 04)

Nesse contexto, existe uma situação de rígido controle do trabalho informal com importante diminuição do número de trabaIhadores na área sem que fossem colocadas alternativas para a sobrevivência daqueles que foram impedidos de trabalhar. A fiscalização é realizada muitas vezes com violência, contando com o braço armado da GCM nas operações de "choque de ordem", como pude, inclusive, observar diretamente durante a pesquisa de campo.

Nesse ponto algumas observações são necessárias. A repressão não é o único modo de 
gestão e controle do trabalhador informal. A compreensão do neoliberalismo como governamentalidade com fortes impactos na subjetividade coletiva, especialmente no mundo do trabalho, mobiliza a noção de "fabricação de sujeitos neoliberais" (DARDOT, LAVAL, 2016).

Assim, todo trabalhador vira um "empreendedor de si mesmo", que deve ser eficiente e esforçado em busca do sucesso. Esse processo de gestão não se sustenta apenas pela sua força ideológica, mas joga com as condições estruturais negativas do mercado de trabalho, transformando-se em importante vetor de reprodução de um processo geral de precarização e intensificação do trabalho. Além disso, a perspectiva empreendedora oculta os processos de exploração e precarização, tendo como consequência política a individualização do trabalho e do sucesso/ fracasso do trabalhador, fragilizando as possibilidades de organização coletiva, substituídos por dinâmicas lúdicas promovidas pelas empresas e literatura de auto-ajuda em suas variadas versões.

As tensões em torno das formas de gestão do trabalho informal no Centro de Salvador oferecem elementos para pensar a questão concretamente, especialmente através do programa "Território Empreendedor - Centro". O programa tem como objetivo a "requalificação econômica, social, e de infraestrutura na região central de Salvador". É um projeto coordenado pela Secretaria de Ordem Pública, em parceria com o Sebrae, o Senac e a Câmara de Dirigentes Lojistas (CDL) de Salvador. A então secretária de ordem pública explicou:

Sou administradora de empresas, eu trouxe muito a questão do fomento ao empreendedorismo na cidade. Busquei formar parceria com o Sebrae, nós criamos um programa que chama "Território Empreendedor", que atua na Barra, Largo 2 de Julho, Av. Sete e Centro Histórico, onde visa o desenvolvimento integrado do território, então nós vamos trabalhar o empreendedorismo, a economia criativa, o turismo, prevenção a violência e cada eixo de atuação tem sido construídos por território, cada território cria suas ações nesses eixos. Então o eixo de turismo para o Pelourinho é diferente, as ações definidas no eixo de turismo do Pelourinho são diferentes das ações definidas no eixo da Barra, Avenida Sete ou Centro da cidade, que não necessariamente precisa ter os mesmos eixos, mas tradicionalmente aqui em Salvador tem caminhado nesses eixos: cultura e turismo, preservação do patrimônio, empreendedorismo, cultura, economia criativa, prevenção à violência (Entrevista 04)

As características gerais do programa chamam atenção. Em Salvador a lógica empreendedora vem acompanhada do "choque de ordem" em espaços como Avenida Sete de Setembro. Por outro lado, a iniciativa privada, através da CDL, participa ativamente das intervenções. Nesse contexto, a organização política dos camelôs só é legitimada com a mediação e intervenção da SEMOP, que criou uma "associação" para representar os ambulantes da Avenida Sete de Setembro:

Hoje, quando eu quero falar sobre Avenida Sete, eu chamo a associação. São onze diretores e cada um representa uma área da Avenida Sete. Então não preciso me reunir todas às vezes com todos os ambulantes. E cada um passa para sua área. Nós criamos esse modelo de governança. Cada área tem seu líder, que não é chefe. Eu não quero chefe. A gente precisa de 
alguém motivador, que entenda a filosofia e trabalhe em rede. E os critérios foram esses. Criamos essa associação que é quem faz a interlocução com o Estado, município no caso. E o critério utilizado para o ordenamento é quem já tem a licença está garantido. E a antiguidade (Entrevista 04).

Nesse processo o "camelô" licenciado é "elevado" ao posto de micro-empreendedor, uma prática discursiva que oculta a precarização do trabalho; os ambulantes expulsos, por sua vez, são problema de "ordem" e "segurança". O discurso empreendedor, desse modo, fomenta a competitividade e fragmenta as organizações políticas combativas, sendo uma poderosa ferramenta de gestão sócio-espacial.

Outro ponto fundamental é a natureza ilusória dos discursos de controle total. Em que pese o "choque de ordem", que é real e tem resultados visíveis no espaço do Centro, o trabalho de rua não regulamentado não acabou. A questão é identificar o controle útil do ponto de vista sócio-espacial, o controle da boa ou má circulação (FOUCAULT, 2008) de pessoas e mercadorias, a depender do espaço e contexto em que essa circulação se desenrola.

Assim, é possível observar locais no Centro onde quase todos os ambulantes eram credenciados e a fiscalização era intensa e cotidiana, como no Terreiro de Jesus; e lugares onde o mercado informal segue "desordenado", funcionando intensamente, mas com trabalhadores atentos à eventual chegada do "rapa", da SEMOP e da Guarda Municipal. Essa dinâmica, por sua vez, não tem relação direta com o "combate" a "criminalidade" e "pirataria". Existem alguns mercados informais no Centro, como o localizado na Rua
Coqueiros da Piedade, ao lado da sede da OAB-BA, que se notabiliza pela venda de eletrônicos e tênis falsificados, mas funciona com apoio da prefeitura.

É nesse ponto, inclusive, que se localiza a força da noção de ilegalismos, pois a questão não é a repressão total, mas a ativação através do discurso e da prática repressiva de uma gestão diferenciada, que habilita politicamente a potência do poder punitivo configurador.

As questões relacionadas aos circuitos das drogas no espaço do Centro Antigo também emergiram como muita força nos discursos institucionais.A droga da vez, o crack, apareceu como elemento chave nas narrativas sobre os problemas de "criminalidade" na área. $O$ comandante do $18^{\circ}$ Batalhão discutiu o crack de modo ambivalente. De um lado, o uso do crack como uma atividade criminosa per si e que, o que é mais grave na visão dele, é a causa dos "delitos de ganância" ${ }^{13}$ contra turistas. "A criminalidade de rua", por sua vez, é, segundo ele, a principal causa de o Centro "não ser o que poderia". De outro lado, a convivência diária com usuários de crack faz com que ele reconheça no uso da droga um "problema social".

A construção e a reprodução de estereótipos relacionados ao crack, por sua vez, também legitimam intervenções contra pessoas em situação de rua:

Um problema grande. As pessoas pensam que o morador de rua é a falta da casa, mas não é. Já foi feita pesquisa que mais de 90 \% tem família e residência. Eles estão na rua por outro motivo. Não por falta da residência. Às vezes o poder

O jargão policial no $18^{\circ} \mathrm{COM}$ identifica os crimes contra o patrimônio como "delitos de ganância". Essa expressão, recorrente ao longo do meu diálogo com o comandante, é especialmente usada em relação aos furtos cometidos por pessoas da região contra turistas. 
público da a moradia e eles vão e depois saem. Tem o grande problema hoje que é crack. Dependência química. Não tenho dúvidas disso.Boa parte deles são dependentes químicos e nós não temos centro de acolhimento. (Entrevista 04)

Esse discurso que associa automaticamente a pessoa em situação de rua com as drogas e a "criminalidade" reforça estereótipos e invisibiliza a questão social. A criminalização do crack produziu algumas das campanhas públicas mais violentas e estigmatizantes do último período. As campanhas da guerra às drogas na Bahia são tributárias da "pedagogia do terror" (NERY FILHO, 2010). Em Salvador foram expostos outdoors e busdoors sugerindo que $80 \%$ das mortes violentas na Bahia estavam relacionadas com a droga, sem nenhuma especificação de natureza metodológica. Nessa mesma peça publicitária uma foto de um pé com a etiqueta do Instituto Médico Legal ou, em outra versão, uma mãe chorando o filho morto "pelo crack". Em outra peça publicitária que também se espalhou pela cidade a sentença é taxativa: "Crack: é cadeia ou caixão".

Uma pesquisa sobre as interfaces entre o crack e a exclusão social nas cidades brasileiras, fruto da parceria entre a Fundação Osvaldo Cruz e Universidade Federal Fluminense, coordenada por Jessé de Souza, apresentou um interessante panorama do uso da droga no espaço urbano brasileiro, descortinando os mitos que naturalizamo vínculo do crack com a violência e apontando criticamente para a relação insidiosa da droga com a opressão social:

(...) exclusão social e o uso do crack provavelmente formam um ciclo vicioso que se retroalimenta e, pior, estende seus efeitos àqueles que sequer fazem uso da droga.Coerentemente, quando perguntados pelos pesquisadores sobre o que esperavam de um tratamento para o seu problema com as drogas, os usuários responderam com a reivindicação de um verdadeiro pacote de direitos sociais, para além de serviços de saúde: moradia, educação,emprego, alimentação, banho etc. A resposta poderia ser a mesma vinda de qualquer jovem das periferias brasileiras. A hipótese que formulamos foi que não só a exclusão social parecia agravar as consequências do uso do crack, como também o pânico social criado em torno do crack estaria contribuindo para a naturalização da desigualdade no Brasil (GARCIA, 2016, p. 14).

Por outro lado, essa e outras pesquisas empíricas questionam a afirmação corrente de que pessoas em situação de rua são naturalmente dependentes químicos. Essas objetificações, assim, reforçam estereótipos, dinamizam processos criminalizadores e violências institucionais.

Todo o panorama apresentado reflete um amplo processo de criminalização da conflitividade social na área central de Salvador com decisivos impactos da produção do espaço na região. Chamou atenção, nesse contexto, a percepção dos agentes da ordem pública em torno da questão. Quando indaguei o guarda civil municipal que lidera o Grupo de Apoio ao Turista, unidade territorial da Guarda Municipal no Centro Histórico, sobre quais eram as maiores dificuldades da atuação da guarda naquele espaço, ele afirmou que “(...) o grande desafio é que a guarda e a PM assumem questões sociais e criminais. Essas questões se interligam. Como não tem outros órgãos, eles que tem que dar conta de moradores de ruas, menores abandonados e usuários de drogas" (Entrevista 03). 
Nessa mesma direção, o Comandante do $18^{\circ}$ Batalhão da Polícia Militar fez, ao longo da entrevista, referências sobre o acúmulo de tarefas da Polícia Militar na região do Centro. Ele explicitou o desgaste do corpo policial em ter que "dar conta" de problemas tão diversos, muitas vezes sem possuir estrutura nem pessoal adequados.

Nesse ponto, o Comandante destacou, por exemplo, o problema com "loucos e psicóticos que andam pelo Centro fazendo confusão". Diante da ausência de alternativas, disse que a polícia é quem tem que "dar conta". A crítica à falta de assistência e suporte do poder público para esses casos é direcionada para os discursos antimanicomiais: segundo ele, "esse negócio de não internar é coisas de estudioso". Por outro lado, disse que "figuras de todo o tipo" vão ao Centro por que ali tem "comida fácil" e prostituição. Afirmou que as famílias negras são as que mais sofrem com a violência cotidiana no Centro, mas relacionou diretamente o problema com a movimentação cultural e política dos negros - especialmente no Centro Histórico - que, segundo ele, tem que parar de fomentar "esse discurso que odeia brancos e policial". Segundo ele, os negros norte-americanos "entenderam sua situação" estudaram e trabalharam, "diferente do que acontece aqui em Salvador". Em sua opinião, essa outra atitude é que faz com que nos Estados Unidos e na Europa não existam "esse pessoal roubando coisas e pedindo dinheiro na rua".

A narrativa do comandante teve um sentido de defesa da corporação e desabafo sobre o acúmulo de tarefas. É fundamental, contudo, destacar que os agentes da ordem percebem a tensão entre questões sociais e tratamento punitivo, mesmo que o discurso não se afaste do paradigma punitivo, muito ligado à consolidação de estereótipos e modulado pelo racismo institucional.

\section{CONSIDERAÇÕES FINAIS: RECOLOCANDO O PROBLEMA}

Esse trabalho partiu do desafio teórico de pensar a questão criminal a partir da cidade. A cidade não como palco ou tela de fundo dos processos de criminalização, mas como plano de referência central; o espaço urbano em sua "inércia dinâmica" (SANTOS, 2005) como elemento chave na configuração das relações sociais, inclusive as relações de desvio e criminalização. Ao fim, mais do que conclusões, acho que estou em condições de recolocar o problema em termos mais precisos.

Como discutido ao longo do texto, o fato de o poder punitivo atuar na produção de espacialidades não é uma novidade. A incidência do poder punitivo como elemento estruturador do espaço urbano, assim, apresenta diversas possibilidades analíticas. Aqui, destaquei como a própria atividade cotidiana das agências de controle produz e reproduz dinâmicas sócio-espaciais, diante do potencial configurador de seu discurso e de sua atuação estruturalmente seletiva.

O processo de produção do espaço através do poder punitivo no Centro de Salvador, contudo, possui características particulares. A atuação das forças e ordem nessa área está profundamente vinculada à gestão do espaço urbano. Assim, os processos de criminalização são orientados pelo embaraIhamento discursivo entre desordem sócio-espacial e criminalidade, o que produz, por sua vez, a potencialização das agências de controle punitivo como agentes da configuração territorial.

Nesse sentido, a configuração do espaço 
urbano a partir da ativação de dispositivos punitivos produz uma arquitetura urbana marcada pela intolerância como "outro" e com as condutas que são politicamente definidas como desvios da ordem pública e da segurança.

O uso político das noções de "desordem" ou "criminalidade" como pontos de referência na leitura de um espaço social, a partir da centralidade de agenciamentos institucionais punitivos, tende à fragmentação e homogeneização desse espaço social. $\mathrm{Na}$ conjuntura atual de Salvador, a dinâmica de policização do urbano se articula finamente com o projeto de cidade que está na pauta política. A colonização da cidade com ênfase aqui na área central pela prática e lógica de controle social punitivo, assim, é um movimento que radicaliza, a partir do signo da violência institucional, processos sociais de segregação e privatização do espaço urbano. Essa é a chave de leitura mais geral em torno da questão.

Ocorre que as "fantasias de controle total" (NEDER, 2007) agora reatualizadas por novas roupagens discursivas e novos sujeitos, são parte de uma retórica institucional descolada da realidade cotidiana da cidade. A policização do urbano e a intensificação das práticas de controle social no Centro de Salvador são movimentos percebidos com destaque, com efeitos concretos na paisagem social da região, além de autorizarem a antecipação de tendências relativas a grandes transformações sócio-espaciais nos próximos períodos.

O ponto, contudo, é que o controle dos desvios, é feito a partir de uma gestão diferencial dos ilegalismos urbanos, a depender de contextos sócio-espaciais e temporais muito específicos. A percepção dessa dinâmica "diferenciada" afasta a ideia de que o espaço é produzido a partir da "repressão total" das condutas indesejadas. Mas, ao contrário do que pode parecer em uma primeira mirada, reforça a potência dos mecanismos de controle na configuração sócio-espacial, pois o poder punitivo é muito mais um dispositivo de gestão do que de repressão.

Assim, a prática-discursiva do choque de ordem e segurança no Centro não reprime, nem efetivamente se propõe a reprimir, todos os ilegalismos, mas se apresenta como principal modus operandi de controle sócio-espacial, com importantes impactos na produção diferenciada de espacialidades. Note-se, contudo, que a relação controle e conflito é sempre dialética. Assim, um aspecto central do fracasso do controle total é o conflito cotidiano produzido pelos "resistentes à ordem", para usar a expressão de Rosa Del Olmo (2004), que mesmo com as investidas do poder punitivo, de diferentes maneiras reinventam o seu lugar no espaço urbano policizado.

Em um dos dias da pesquisa de campo, parei na Avenida Sete de Setembro para tomar uma água de coco. Conversando com o vendedor, ele me disse que a GCM e a SEMOP estavam "jogando duro" na área. Ele não era licenciado e estava trabalhando de forma irregular. Disse que estava juntando dinheiro para tentar se regularizar, mas estava aproveitando que naquele período (era mês de eleição municipal) a fiscalização era "frouxa". A prefeitura tinha medo do desgaste político causado pelas operações ${ }^{14}$.

Relembro esse diálogo para destacar que esse trabalho foi construído basicamente

${ }^{14}$ A percepção do ambulante, cabe destacar, foi depois confirmada pela secretária de ordem pública, que durante a entrevista falou que na época de campanha eleitoral a secretaria trabalha em ritmo de "operação tartaruga", para evitar o que segundo ela é a "politização" das operações de ordenação (Entrevista 05). 
pela minha interpretação dos discursos e observação das práticas institucionais. Essa foi uma opção metodológica condicionada pelo interesse que as práticas institucionais despertam para o campo dos estudos sociojurídicos e, também, pelas condições materiais de realização da pesquisa. Essa perspectiva possibilitou uma visão ampla do processo social estudado com ênfase na identificação e interpretação do "projeto de ordem e segurança" do Centro da cidade, e uma avaliação da atuação prático-discursiva do poder punitivo como agente de produção dessa espacialidade.

Por outro lado, a abordagem apresenta limites. A pesquisa de campo mostrou como as dinâmicas de controle são profundamente atravessadas por interações extra-oficias, conflitos e negociações que muitas vezes extrapolam as regras e, inclusive, as metaregras que de uma forma geral orientam os processos institucionais de criminalização. Esses contextos, por sua vez, parecem complexificar as relações de conflito e controle, devendo ser incorporadas em um quadro mais geral de interpretação. Assim, além dos discursos institucionais, analisados através das lentes acadêmicas, outras narrativas podem ser decisivas para uma interpretação mais completa desses processos. Os discursos e as percepções dos "resistentes", nesse sentido, podem apontar para problemas não identificados, relativizar certezas e, sem dúvida, complexificar a análise.

Essas considerações fazem parte dessa recolocação do problema em perspectiva crítica. Elas abrem novas possibilidades, novas agendas de pesquisa e novos horizontes de interpretação - em um contexto de progressivo policização do urbano - do poder punitivo como dispositivo que produz e configura espaços, territórios e lugares na cidade.

\section{REFERÊNCIAS}

Andrade, V.(2012).Pelas Mãos da Criminologia:O controle penal para além da (des)ilusão. Rio de Janeiro: Revan.

Arantes, O.(2000).Uma estratégia fatal: a cultura nas novas gestões urbanas. In: Arantes, O; Maricato; E; Vainer, C. (Orgs). A Cidade do Pensamento Único:desmanchando consensos. $3^{a}$ ed. Petrópolis: Editora Vozes.

Bairros, L.(1988).Pecados no "paraíso racial". O negro na força de trabalho na Bahia. In: Reis, J. (Org.). Escravidão e Invenção da liberdade: Estudos sobre o negro no Brasil.São Paulo: Brasiliense.

Baratta, A. (2011). Criminologia Crítica e Crítica ao Direito Penal: Introdução à sociologia do direito penal. Trad. Juarez Cirino. 6. ed. Rio de Janeiro: Revan: Instituto Carioca de Criminologia.

Batista, V. (2003). Difíceis ganhos fáceis:drogas e juventude pobre no Rio de Janeiro. Rio de Janeiro: Revan.

Carvalho, I; Pereira, G.(2014). Salvador como negócio. In:_Metrópoles na atualidade brasileira. Salvador: Edufba..

Dardot, P.; Laval, C.(2016).A Nova Razão do Mundo:ensaio sociedade neoliberal.São Paulo: Boitempo.

Del Olmo, R. A. (2004).América Latina e sua criminologia. Rio de Janeiro: Revan.

Foucault, M. (1987). Vigiar e Punir. Petrópolis: Vozes. (2008).Segurança, Território, População.São Paulo: Martins Fontes.

Garcia, A. (2009). Desigualdades raciais e segregação urbana em antigas capitais: Salvador, cidade D'Oxum e Rio de Janeiro, cidade de Ogum. Rio de Janeiro: Faperj.

Laville, C; Dionne, J. (1999). A Construção do Saber: manual de pesquisa em ciências humanas. Adaptação da obra: Lana Mara Siman. Trad.: Heloisa Monteiro e Francisco Settineri. Porto Alegre: Artmed.

Neder, G. (2007).Iluminismo Jurídico-Penal Luso-Brasileiro:obediência e Submissão. Rio de janeiro: Revan. Reis, J. (1989)O levante dos Malês: uma interpretação política. In: Reis, J; Silva, E. (Orgs.). Negociação e conflito: A resistência negra no Brasil escravista. São Paulo: Companhia das Letras.

Santa'nna, M. (2003). A recuperação do centro histórico de Salvador: Origens, sentidos e resultados. Revista de Arquitetura e Urbanismo, v. 8, p. 44-59.Santos, M. 
(2005). Da totalidade ao lugar. São Paulo: Edusp..

Silva, E.(1989).Entre zumbi e pai João, o escravo que negocia. In: Reis, J; Silva, E. (Orgs.). Negociação e conflito: A resistência negra no Brasil escravista. São Paulo: Companhia das Letras.

Telles, V. (2010). A cidade nas fronteiras do legal e ilegal. Belo Horizonte: Fino Traço Editora..

(2015). Cidade: Produção de espaços, formas de controle e conflito. Revista de Ciências Sociais, Fortaleza, v. 46, n.1.

Vargas, J.H. (2013). As lutas por territórios negros do Rio de Janeiro. In: Oliveira, R. (org.). A cidade e o negro no Brasil: cidadania e território. São Paulo: Alameda. Zaffaroni, R., Batista, N., et al. (2011). Direito Penal Brasileiro:Primeiro Volume: Teoria Geral do Direito Penal. Rio de Janeiro: Revan.

Data de submissão: 09/05/2018

Data de aceite: 08/12/2019 